\title{
COMPARISON OF UWIN SCORE WITH INTERNATIONAL PROSTATIC SYMPTOM SCORE IN PATIENTS WITH LOWER URINARY TRACT SYMPTOMS
}

\author{
Karunamoorthy Ramaraju, Karthik Rajan², Sudhakar Kalyanasundaram³, Ilamparuthi Chennakrishnan 4
}

${ }^{1}$ Assistant Professor, Department of Urology, Madras Medical College.

${ }^{2}$ Postgraduate, Department of Urology, Madras Medical College.

3Postgraduate, Department of Urology, Madras Medical College.

4 Professor, Department of Urology, Madras Medical College.

\section{ABSTRACT}

\section{BACKGROUND}

Benign Prostatic Hyperplasia (BPH) is a common disease causing bothersome symptoms. The AUA Symptom Index or the identical IPSS is recommended for symptom assessment in each patient presenting with BPH. Though it has been validated it requires some explanation, especially for people with limited education. In this study, we evaluated the agreement and correlation between IPSS and UWIN to determine whether the reduced questionnaire could reliably be used instead of IPSS.

\section{MATERIALS AND METHODS}

A total of 300 patients with LUTS completed the IPSS and UWIN questionnaire. The patients feel about the two questionnaires, i.e. easy understanding, ability to fill without help, literacy of the patient, time taken, completeness of information were also recorded. Statistical analysis was performed; the scores of each participant on AUA-SS (range 0 to 35) and UWIN (range 0 to 12) were calculated and evaluated using Spearman's correlation coefficients. Bland-Altman plots were also used into determining whether UWIN and IPSS total scores were in agreement.

\section{RESULTS}

The Spearman correlation coefficient was calculated for both the scores (Table 3), i.e. the IPSS and UWIN score and it was 0.913 $(\mathrm{p}<0.0001)$ which states that both the scoring system are in good correlation. Bland Altman plot of IPSS vs. UWIN showed that both the system were said to be in agreement if the values plotted are within the confidence limit. The pre-treatment IPSS and UWIN score were in good agreement for the 300 participants (Fig. 4). Similarly, the post-treatment IPSS and UWIN score were also in good agreement. The time taken for filling up the charts for IPSS score was average of 18 minutes (14-26 minutes). The time taken for filling up the charts for UWIN score was average of 10 minutes (8-18 minutes).

\section{CONCLUSIONS}

In daily clinical practice the use of patient's questionnaires can be limited by questionnaire length and the burden that it places on the respondent to read, understand and answer all questions. Our study has shown that the UWIN scoring system for LUTS is equivalent to the gold standard IPSS.

\section{KEYWORDS}

UWIN, IPSS, Benign Prostatic Hyperplasia.

HOW TO CITE THIS ARTICLE: Ramaraju K, Rajan K, Kalyanasundaram S, et al. Comparison of UWIN score with international prostatic symptom score in patients with lower urinary tract symptoms. J. Evolution Med. Dent. Sci. 2016;5(80):5942-5946, DOI: $10.14260 /$ jemds/2016/1342

\section{BACKGROUND}

Benign Prostatic Hyperplasia (BPH), one of the most common diseases of aging men. It can be associated with bothersome Lower Urinary Tract Symptoms (LUTS). It also affects quality of life by interfering with normal daily activities and sleep patterns. ${ }^{1}$ The prevalence of histopathologic BPH is age dependent with initial development usually after 40 years of age. By 60 years of age, its prevalence is greater than $50 \%$ and by age 85 is as high as $90 \% .^{2,3}$ The prevalence of bothersome symptoms also increases with age. The impact of LUTS on the patient's quality of life is highly variable.

Financial or Other, Competing Interest: None.

Submission 30-07-2016, Peer Review 10-09-2016,

Acceptance 19-09-2016, Published 04-10-2016.

Corresponding Author:

Dr. Karunamoorthy Ramaraju,

No. 2130, Arya Flat 2B,

$12^{\text {th }}$ Main Road, L Block,

Anna Nagar, Chennai-600040.

E-mail: drrkaruna@yahoo.co.in

DOI: 10.14260/jemds/2016/1342
They are not directly related to any measurable physiological factors. The patient's perception of the severity of the condition as well as the degree to which it interferes with his lifestyle or causes embarrassment should be the primary consideration in choosing therapy.4,5

The AUA Symptom Index or the identical IPSS is recommended for symptom assessment in each patient presenting with BPH.6 ${ }^{6}$ It is superior to an unstructured interview in quantifying symptom frequency and severity. Using seven questions that relate to associated symptoms, classification ranges from mild ( 0 to 7 ) to moderate (8 to 19) or severe (20 to 35 ). Some patients may require an explanation of the questions to adequately understand their intent. Although validated for its clarity, test/retest reliability, internal consistency and criteria strength, this tool is not a replacement for personal discussion of symptoms with the patient.

To decrease the burden of AUA-SS on respondents and clinicians we have used new, decreased symptom questionnaire called UWIN ${ }^{7}$ (Urgency, Weak stream, Incomplete emptying and Nocturia). 
Instead 8 questions as used previously by IPSS, UWIN uses only 4 questions and the quality of life question for a total of 5 . In this study, we evaluated the agreement and correlation between IPSS and UWIN to determine whether the reduced questionnaire could reliably be used instead of IPSS. If so, UWIN would decrease the burden on the respondent and make administering the questionnaire more efficient.

\section{MATERIALS AND METHODS}

This study was conducted in a tertiary care centre for a period of one year from February 2014 to February 2015. Ethical clearance was taken from the Institute Ethics Committee prior to the start of the study. All patients presenting to the outpatient department with LUTS were included in the study after informed consent and prior approval was taken from the Institute Ethics Committee. Patients with vesical calculus, acute prostatitis, stricture urethra and previous urethral surgery were excluded from the study.

A total of 300 participants completed IPSS (Table 1) and UWIN (Table 2). The patients feel about the two questionnaires, i.e. easy understanding, ability to fill without help, literacy of the patient, time taken and completeness of information were also recorded.

This sample size was large enough for statistical validation and small enough to minimise to ignorable levels any bias. Statistical analysis was performed the scores of each participant on AUA-SS (range 0 to 35) and UWIN (range 0 to 12) were calculated and evaluated using Spearman's correlation coefficients. Bland-Altman plots were also used into determine whether UWIN and IPSS total scores were in agreement. In this graphical method, the differences between the two techniques are plotted against the average of the two techniques. This method is considered as gold standard. The IPSS score of each participant is divided by 35 (maximum score of IPSS) and UWIN score of each participant is divided by 12 (maximum score of UWIN). Thus, the values are rescaled between 0 and 1 . The graph is plotted in $X$ and $Y$ axis, IPSS+UWIN/2, IPSS-UWIN respectively. Statistical significance was considered if $\mathrm{p}<0.0001$. Similar analysis was also done in the post-treatment scenario. The same questionnaires, both IPSS and UWIN score were given to the patients irrespective to the mode of management and their current status was also compared by the same statistical method. The uroflowmetry was performed before and after surgery were also taken into consideration and the relationship between IPSS score and UWIN score along with Q-max were also analysed.

\section{RESULTS}

The average age of the study population was 60.4 years. Among the patients, the literacy rate was also collected. Most of the patients had at least completed middle school (73.3\%) and were able to complete both the IPSS and UWIN questionnaires with no or minimal assistance.

The Spearman correlation coefficient was calculated for both the scores (Table 3), i.e. the IPSS and UWIN score and it was $0.913(\mathrm{p}<0.0001)$ which states that both the scoring system are in good correlation. Similarly, the post-treatment IPSS score and UWIN score were subjected to the review of Spearman correlation coefficient and it was found to be 0.942 $(\mathrm{p}<0.0001)$.
The quality of life index of the IPSS scoring system and the quality of life index of UWIN scoring system were also compared and they also found to be in correlation and the correlation coefficient was $0.856(\mathrm{p}<0.0001)$. Similarly, the post-treatment the quality of life index of the IPSS scoring system and the quality of life index of UWIN scoring system were also compared and they also found to be in correlation and the correlation coefficient was 0.914 ( $p<0.0001)$. The Qmax was also compared with the UWIN score whether the degree of obstruction was in correlation and it was found to be 0.902 ( $\mathrm{p}<0.0001)$. Similarly, the post-treatment the Q-max was also compared with the UWIN score whether the degree of obstruction was in correlation and it was found to be 0.933 (p<0.0001).

Bland Altman plot of IPSS vs. UWIN showed that both the system were said to be in agreement if the values plotted are within the confidence limit. The pre-treatment IPSS and UWIN score were in good agreement for the 300 participants (Fig. 4). Similarly, the post-treatment IPSS and UWIN score also in good agreement. The Quality of Life index of IPSS and Quality of Life index of UWIN were also compared both before and after treatment and found to be in good agreement in the pretreatment data. This was done so because the responses to both systems vary widely from 7 responses in the IPSS system and only 3 in the UWIN system and irrespective of this fact the scores seems to be in good agreement.

The time taken for filling up the charts for IPSS score was average of 18 minutes (14-26 minutes). The time taken for filling up the charts for UWIN score was average of 10 minutes (8-18 minutes).

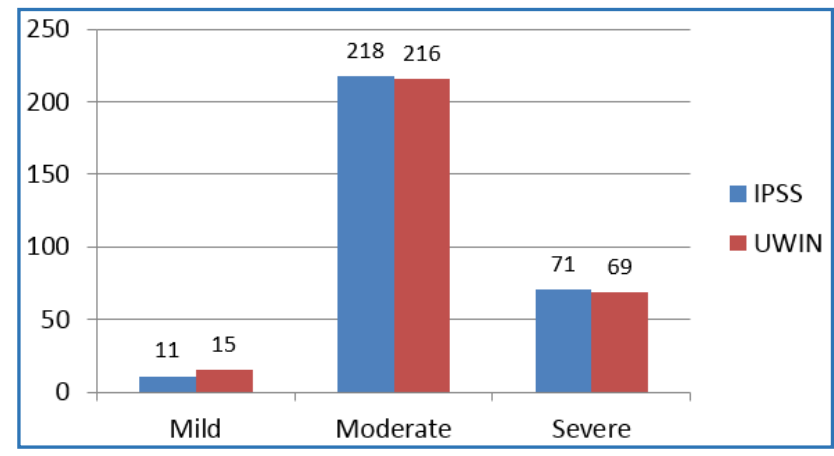

Fig. 1: Pre-Treatment IPSS and UWIN Scores

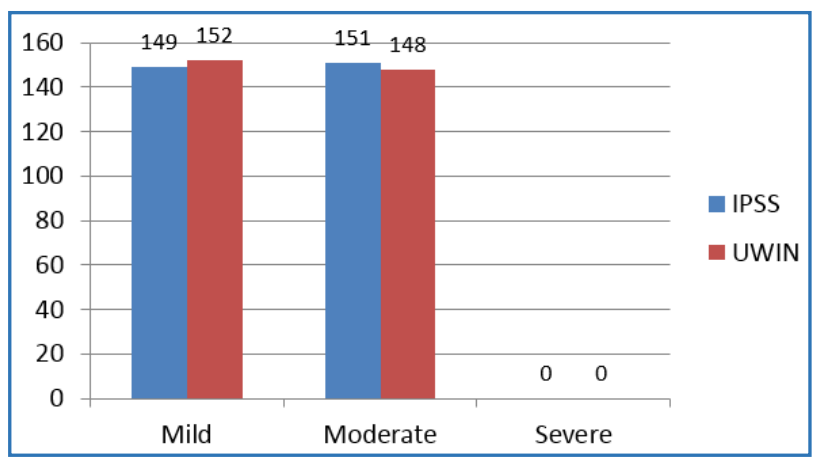

Fig. 2: Post-Treatment IPSS and UWIN Scores 


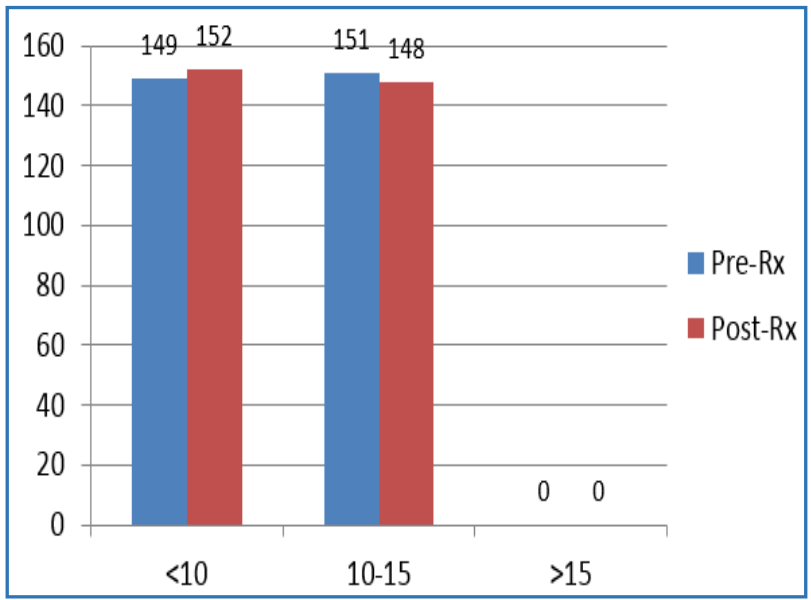

Fig. 3: Q-Max Values Pre- and Post-Treatment

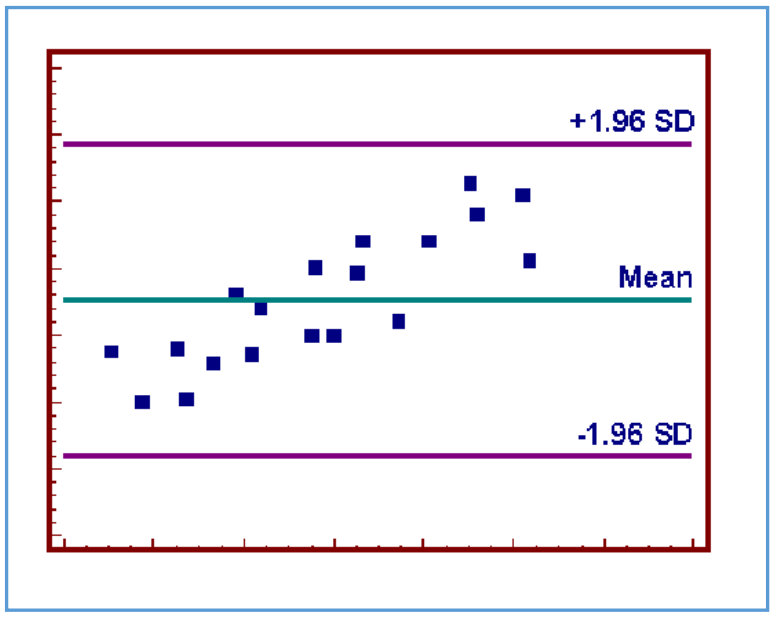

Fig. 4: Bland-Altman Plot of IPSS vs. UWIN

\begin{tabular}{|c|c|c|c|c|c|c|c|}
\hline $\begin{array}{c}\text { In the past } \\
\text { month: }\end{array}$ & $\begin{array}{l}\text { Not at } \\
\text { All }\end{array}$ & $\begin{array}{l}\text { Less than } \\
1 \text { in } 5 \\
\text { Times }\end{array}$ & $\begin{array}{l}\text { Less than } \\
\text { Half the } \\
\text { Time }\end{array}$ & $\begin{array}{c}\text { About } \\
\text { Half } \\
\text { the } \\
\text { Time }\end{array}$ & $\begin{array}{l}\text { More } \\
\text { than Half } \\
\text { the Time }\end{array}$ & $\begin{array}{l}\text { Almost } \\
\text { Always }\end{array}$ & $\begin{array}{l}\text { Your } \\
\text { score }\end{array}$ \\
\hline $\begin{array}{l}\text { 1. Incomplete Emptying } \\
\text { How often have you had the } \\
\text { sensation of not emptying } \\
\text { your bladder? }\end{array}$ & 0 & 1 & 2 & 3 & 4 & 5 & \\
\hline $\begin{array}{l}\text { 2. Frequency } \\
\text { How often have you had to } \\
\text { urinate less than every two } \\
\text { hours? }\end{array}$ & 0 & 1 & 2 & 3 & 4 & 5 & \\
\hline $\begin{array}{l}\text { 3. Intermittency } \\
\text { How often have you found } \\
\text { you stopped and started again } \\
\text { several times when you } \\
\text { urinated? }\end{array}$ & 0 & 1 & 2 & 3 & 4 & 5 & \\
\hline $\begin{array}{l}\text { 4. Urgency } \\
\text { How often have you found it } \\
\text { difficult to postpone } \\
\text { urination? }\end{array}$ & 0 & 1 & 2 & 3 & 4 & 5 & \\
\hline $\begin{array}{l}\text { 5. Weak Stream } \\
\text { How often have you had a } \\
\text { weak urinary stream? }\end{array}$ & 0 & 1 & 2 & 3 & 4 & 5 & \\
\hline \multirow{2}{*}{$\begin{array}{l}\text { 6. Straining } \\
\text { How often have you had to } \\
\text { strain to start urination? }\end{array}$} & 0 & 1 & 2 & 3 & 4 & 5 & \\
\hline & None & 1 Time & 2 Times & 3 Times & 4 Times & 5 Times & \\
\hline $\begin{array}{l}\text { 7. Nocturia } \\
\text { How many times did you } \\
\text { typically get up at night to } \\
\text { urinate? }\end{array}$ & 0 & 1 & 2 & 3 & 4 & 5 & \\
\hline $\begin{array}{l}\text { Total I-PSS } \\
\text { Score }\end{array}$ & & & & & & & \\
\hline
\end{tabular}

Table 1: AUA-SS (IPSS) Questionnaire 


\begin{tabular}{|c|c|c|c|c|}
\hline Question & $\begin{array}{c}\text { Not at } \\
\text { all }\end{array}$ & $\begin{array}{c}\text { Less than } \\
\text { half the time }\end{array}$ & $\begin{array}{c}\text { About half } \\
\text { the time }\end{array}$ & $\begin{array}{c}\text { More than } \\
\text { half the time }\end{array}$ \\
\hline $\begin{array}{c}\text { Urgency: Over the past month } \\
\text { or so, how often have you } \\
\text { found it difficult to postpone } \\
\text { urination? }\end{array}$ & 0 & 1 & 2 & 3 \\
\hline $\begin{array}{c}\text { Weak Stream: Over the past } \\
\text { month or so, how often have } \\
\text { you had a weak urinary } \\
\text { stream? }\end{array}$ & 0 & 1 & 2 & 3 \\
\hline $\begin{array}{c}\text { Incomplete emptying: Over the } \\
\text { past month or so, how often } \\
\text { have you had a sensation of } \\
\text { not emptying your bladder } \\
\text { completely after you finished } \\
\text { urinating? }\end{array}$ & 0 & 1 & 2 & 3 \\
\hline $\begin{array}{c}\text { Nocturia: Over the last month, } \\
\text { how many times did you most } \\
\text { typically get up to urinate from } \\
\text { the time you went to bed at } \\
\text { night until the time you got up } \\
\text { in the morning? }\end{array}$ & 0 & 1 & 2 & 3 \\
\hline $\begin{array}{c}\text { Bothersome: If you were to } \\
\text { spend the rest of your life with } \\
\text { your urinary condition just the } \\
\text { way it is now, how would you } \\
\text { feel about that? }\end{array}$ & Happy & Mixed & Unhappy & NA \\
\cline { 2 - 5 } & 0 & 1 & 2 & NA \\
\hline
\end{tabular}

Table 2: UWIN Score Questionnaire

\begin{tabular}{|l|c|}
\hline \multicolumn{1}{|c|}{$\begin{array}{c}\text { Compared } \\
\text { Variables }\end{array}$} & \multicolumn{1}{|c|}{$\begin{array}{c}\text { Spearman } \\
\text { Co-efficient }\end{array}$} \\
\hline IPSS vs. UWIN pre-treatment & $0.913(\mathrm{p}<0.0001)$ \\
\hline IPSS vs. UWIN post-treatment & $0.942(\mathrm{p}<0.0001)$ \\
\hline $\begin{array}{l}\text { The quality of life index of IPSS vs. } \\
\text { UWIN pre-treatment }\end{array}$ & $0.856(\mathrm{p}<0.0001)$ \\
\hline $\begin{array}{l}\text { The quality of life index of IPSS vs. } \\
\text { UWIN post-treatment }\end{array}$ & $0.914(\mathrm{p}<0.0001)$ \\
\hline $\begin{array}{l}\text { Pre-treatment the Q-max vs. } \\
\text { UWIN score }\end{array}$ & $0.902(\mathrm{p}<0.0001)$ \\
\hline $\begin{array}{l}\text { Post treatment the Q-max vs. } \\
\text { UWIN score }\end{array}$ & $0.933(\mathrm{p}<0.0001)$ \\
\hline \multicolumn{2}{|c|}{ Table 3: Spearman Co-Relation Coefficient } \\
\hline
\end{tabular}

\section{DISCUSSION}

Decreasing the number of questions in a questionnaire can decrease the coverage of its content, affecting its validity.8,9 However, our study shows that decreasing the number of IPSS questions and response levels to construct the UWIN questionnaire retained the reliability and validity of original instrument to collect data on BPH symptom severity. Physicians usually diagnose BPH by clinical symptoms and assess improvement in BPH after treatment by improvement in symptoms. ${ }^{10,11}$ Historically, IPSS has been the gold standard questionnaire to assess the clinical symptoms of BPH.12 We report that the new UWIN questionnaire can be used in place of AUA-SS. Johnson et al found that AUA-SS can be difficult for respondents to interpret. They evaluated 998 patients who self-administered AUA-SS and then had their physician administer it. ${ }^{13}$ As the patient education level increased, patient understanding of IPSS questions also increased. Of men with greater than a high school education, 28\% misreported their total IPSS score by 4 points or more while those with fewer than 9 years of education misreported the score by 4 points or more $58 \%$ of the time. The new UWIN questionnaire excludes the frequency question, which should make UWIN easier for respondents to answer and improve the accuracy of the total score in reflecting patient symptom severity.

However, UWIN includes the urgency question and in future questionnaires attempts should be made to reword this question. Currently, there is a trend toward shortening medical questionnaires. The techniques used to shorten these instruments can include statistical analysis and/or an expert based approach. ${ }^{14}$ Coste et al made recommendations for shortening medical survey instruments after reviewing 42 articles along with their methods of developing shorter instruments. ${ }^{15}$ Recommendations included starting with the gold standard questionnaire and developing the new shorter questionnaire using statistical analysis in one population and a validation study in a second population. 16

In our study, we used the gold standard IPSS questionnaire and performed statistical analysis to create the shortened UWIN questionnaire. Our evaluation revealed a good linear relationship between UWIN and IPSS total symptom scores and quality of life questions. This was done by using Spearman correlation coefficient. We have done it both for pre-treatment and post-treatment scenario also. The correlation was again well established between the two questionnaires. These results were same as mentioned in other studies. ${ }^{17}$ This study further included Q-max vs. UWIN scoring system for comparison and the results were found to be in correlation with both pre-treatment and post-treatment level. However, when evaluating a new questionnaire vs. an established instrument, we must see whether the new instrument agrees with the older questionnaire. We did this using Bland-Altman plots. ${ }^{18}$ In this graphical method, the differences between the two techniques are plotted against the average of the two techniques. This method is considered as gold standard. The IPSS score of each participant is divided by 35 (maximum score of IPSS) and UWIN score of each participant is divided by 12 (maximum score of UWIN). Thus, the values are rescaled between 0 and 1 . The graph is plotted in $\mathrm{X}$ and $\mathrm{Y}$ axis, IPSS+UWIN/2, IPSS-UWIN, respectively. Both the systems were said to be in agreement if the values plotted lies within the confidence limit. The pre-treatment IPSS and UWIN score were in good agreement for the 300 participants. Similarly, the post-treatment IPSS and UWIN score are also in good agreement. The Quality of Life index of IPSS and Quality of Life index of UWIN were also compared and found to be in good agreement in the pre-treatment data. This was done so because the responses to both systems vary widely from 7 responses in the IPSS system and only 3 in the UWIN system. Irrespective of this fact, the scores seems to be in good agreement.

The post-treatment Quality of Life index of IPSS and Quality of life index of UWIN were also compared and found to be in good agreement. Most of the studies did not compare Qmax or with urodynamic study with the scoring system. ${ }^{17}$ In our study, the pre-treatment and post-treatment score of UWIN and Q-max were also compared and subjected to the same test and it was within the confident limit and hence found to be in good agreement. In this study the participants were also questioned about the easiness about both the questionnaires; almost $95 \%$ of the people irrespective of their educational status said UWIN was easier than the IPSS. Even among the less than middle school group, it was felt in the same proportion of the participants that the UWIN questionnaire was easier. One of the reason may be not only 
the reduced number of questions, but also questions were in regional language.

\section{CONCLUSION}

In daily clinical practice, the use of patient's questionnaires can be limited by questionnaire length and the burden that it places on the respondent to read, understand and answer all questions.

Shortening the survey instrument lessens the burden on the respondent and broadens instrument applicability while also making data collection more efficient for clinicians and researchers. Our study has shown that the UWIN scoring system for LUTS is equivalent to the gold standard IPSS.

\section{REFERENCES}

1. Parsons JK, Mougey J, Lambert L, et al. Lower urinary tract symptoms increase the risk of falls in older men. BJU Int 2009;104(1):63-8.

2. Ganpule AP, Desai MR, Desai MM, et al. Natural history of lower urinary tract symptoms: preliminary report from a community-based Indian study. BJU Int 2004;94(3):3324.

3. Groves HK, Chang D, Palazzi K, et al. The incidence of acute urinary retention secondary to BPH is increasing among California men. Prostate Cancer Prostatic Dis 2013;16(3):260-5.

4. Taylor BC, Wilt TJ, Fink HA, et al. Prevalence, severity, and health correlates of lower urinary tract symptoms among older men: the MrOS study. Urology 2006;68(4):804-9.

5. Temml C, Brössner C, Schatzl G, et al. The natural history of lower urinary tract symptoms over five years. Eur Urol 2003;43(4):374-80.

6. Barry MJ, Fowler FJ, O'Leary MP, et al. The American urological association symptom index for benign prostatic hyperplasia. The measurement committee of the american urological association. J Urol 1992;148(5): 1549-57.

7. Barqawi AB, Sullivan KF, Crawford ED, et al. Methods of developing UWIN, the modified American urological association symptom score. J Urol 2011;186(3):940-4.

8. Bukstein DA, McGrath MM, Buchner DA, et al. Evaluation of a short form for measuring health related quality of life among pediatric asthma patients. J Allergy Clin Immunol 2000;105(2):245-51.
9. Ware J, Kosinski M, Keller SD. A 12 item short form health survey: construction of scales and preliminary tests of reliability and validity. Med Care 1996;34(3):220-33.

10. Roehrborn CG, McConnell JD, Barry MJ, et al. AUA guideline on management of benign prostatic hyperplasia (2003). Chapter 1: diagnosis and treatment recommendations. The Journal of urology 2003;170(2):530-47.

11. Black L, Naslund MJ, Gilbert TD, et al. An examination of treatment patterns and cost of care among patients with benign prostatic hyperplasia. Am J Manag Care 2006;12(4Suppl):S99-110.

12. Platz EA, Joshu CE, Mondul AM, et al. Incidence and progression of lower urinary tract symptoms in a large prospective cohort of United States men. J Urol 2012;188(2):496-501.

13. Johnson TV, Abbasi A, Ehrlich SS, et al. Patient misunderstanding of the individual questions of the American urological association symptom score. J Urol 2008;179(6):2291-4.

14. Guillemin F, Bombardier C, Beaton D. Cross-cultural adaptation of health-related quality of life measures: literature review and proposed guidelines. J Clin Epidemiol 1993;46(12):1417-32.

15. Coste J, Guillemin F, Pouchot J, et al. Methodological approaches to shortening composite measurement scales. J Clin Epidemiol 1997;50(3):247-52.

16. Deyo RA, Diehr P, Patrick DL. Reproducibility and responsiveness of health status measures. Statistics and strategies for evaluation. Control Clin Trials 1991;12(4): 142S-58S.

17. Eid K, Krughoff K, Stoimenova D, et al. Validation of the urgency, weak stream, incomplete emptying, and nocturia (UWIN) score compared with the American urological association symptoms score in assessing lower urinary tract symptoms in the clinical setting. Urology 2014;83(1):181-5.

18. Bland JM, Altman D. Statistical methods for assessing agreement between two methods of clinical measurement. The lancet 1986;327(8476):307-10. 